\title{
An integrated approach to study novel properties of a MALDI matrix (4-maleicanhydridoproton sponge) for MS imaging analyses
}

\author{
Davide Corinti ${ }^{1} \cdot$ Maria Elisa Crestoni ${ }^{1} \cdot$ Simonetta Fornarini $^{1} \cdot$ Maren Pieper $^{2} \cdot$ Karsten Niehaus $^{2}$. \\ Marco Giampà ${ }^{2}$ \\ ${ }^{1}$ Dipartimento di Chimica e Tecnologie del Farmaco, Università di Roma "La Sapienza", P.le A. Moro 5, I- \\ 00185 Roma, Italy, European Union. \\ ${ }^{2}$ Center for Biotechnology and Department for Proteome and Metabolome Research, Faculty of \\ Biology, Bielefeld University, Universitätsstraße 25, 33615 Bielefeld, Federal Republic of Germany, \\ European Union. \\ mgiampa@cebitec.uni-bielefeld.de \\ simonetta.fornarini@uniroma1.it \\ Orcid \\ S. Fornarini: 0000-0002-6312-5738 \\ M. E. Crestoni: 0000-0002-0991-5034 \\ D. Corinti: 000-0001-8064-3492 \\ M. Giampà: 0000-0002-8847-9604
}

Electronic supplementary material. The online version of this article contains supplementary material, which is available to authorized users.

\begin{abstract}
The chemical properties accounting for the operation of a valuable matrix used in matrix assisted laser desorption ionization (MALDI) to perform mass spectrometry imaging (MSI), namely 3-(4,5bis(dimethylamino)napthalen-1-yl)furan-2,5-dione (4-maleicanhydridoproton sponge, MAPS), have been elucidated also by comparison with the parent molecule 1,8-Bis(dimethylamino)naphthalene (so-called Proton Sponge, PS). Both compounds present the bis(dimethylamino) groups, apt to efficiently trap a proton imparting positive charge. Only MAPS, though, owns the maleicanhydrido function acting as electrophile and yielding covalently bound adducts with a variety of analytes. In this way MAPS performs as 'carrier' for the analyte $(A)$ of interest, at the same time minimizing the presence of useless, background ions. The covalent character of the adducts, $[\mathrm{MAPS}+\mathrm{H}+\mathrm{A}]^{+}$, is testified by their collision induced dissociation pattern, quite distinct from the one displayed by $[\mathrm{PS}+\mathrm{H}]^{+}$, while PS does not form any $[\mathrm{PS}+\mathrm{H}+\mathrm{A}]^{+}$, thus confirming the key role of the maleicanhydrido functionality of MAPS. Vibrational spectroscopy of [MAPS $+\mathrm{H}+\mathrm{A}]^{+}$adducts $\left(\mathrm{A}=\mathrm{H}_{2} \mathrm{O}, \mathrm{NH}_{3}\right)$ provided further structural evidence. The presence of a mobile proton on $A$ was found to be a requisite for adduct formation by electrospray ionization of acetonitrile solutions, pointing to a possible role of MAPS in discriminating competing analytes based on molecular features. The performance of MAPS has been verified in MALDI-MSI of Atropa belladonna berries, exploiting MAPS binding to atropine.
\end{abstract}

Keywords: MALDI - mass spectrometry imaging $\cdot$ structure elucidation $\cdot$ IR ion spectroscopy $\cdot$ FT-ICR mass spectrometry 


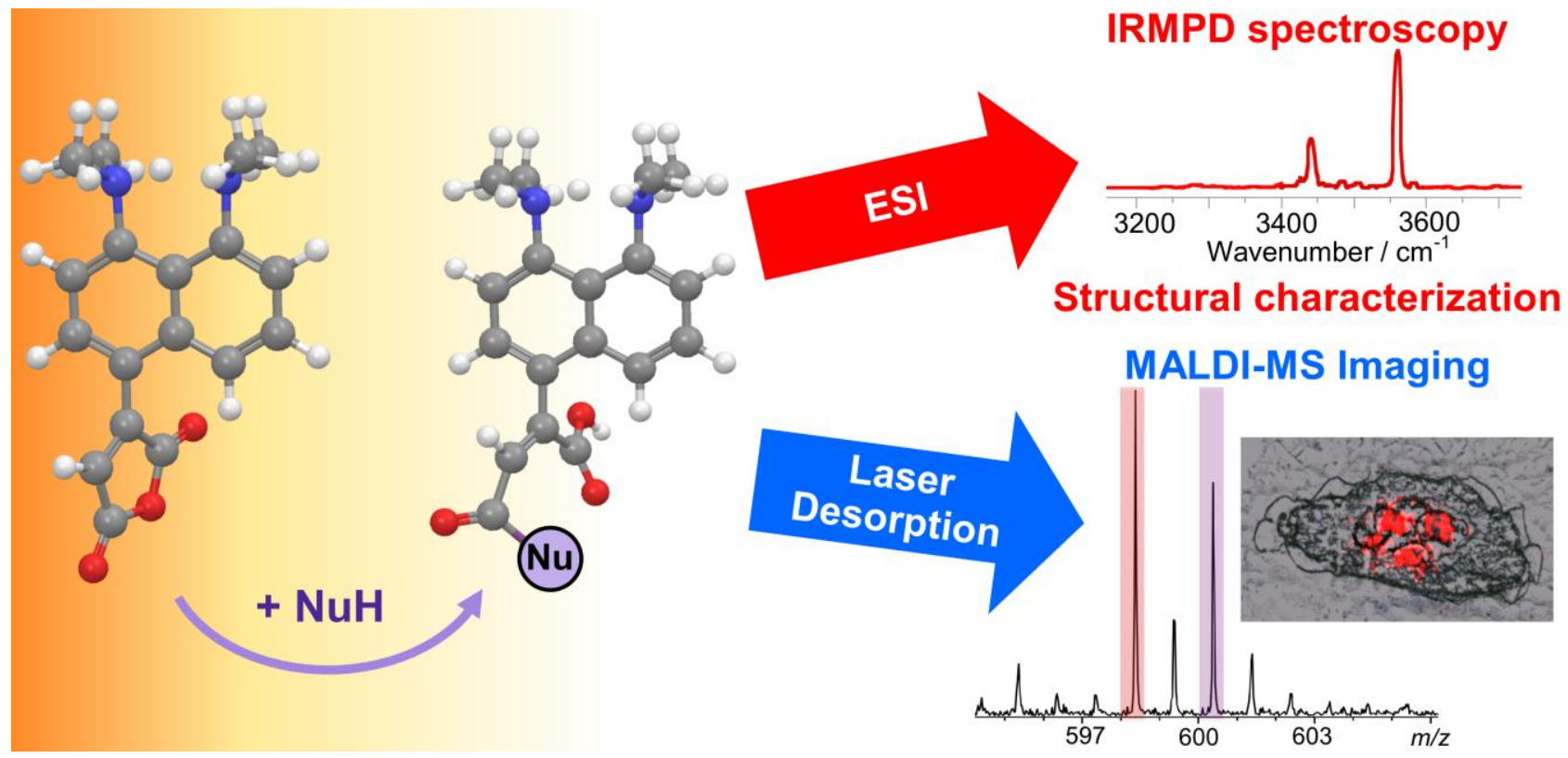




\section{Introduction}

Matrix Assisted Laser Desorption Ionization Mass Spectrometry Imaging (MALDI-MSI) is a promising technique that allows visualization and mapping of several types of compounds directly onto a matrix coated tissue section. Recently MALDI-MSI was used for the visualization of metabolites in different biological specimens in order to discover new diagnostically relevant biomarkers, notably in oncology [1, 2], and to gain insight into the mechanisms of cellular processes [3].

In this scenario, the chemistry of the selected MALDI matrix is a crucial factor for the detection of molecules affecting the performance of the MALDI-MSI procedures [4-7]. The influence of a selected matrix and the mechanisms behind the formation of ions are still largely unknown though.

1,8-Bis(dimethylamino)naphthalene (so-called Proton Sponge, PS) was discovered to be the first MALDI matrix able to detect small acidic compounds without any matrix background [8]. Unfortunately PS is not suitable for typical MALDI-MSI procedures due to its vacuum instability [9]. On the other hand, PS is known to react readily with bromomaleic anhydride to yield 3-(4,5-bis(dimethylamino)napthalen-1-yl)furan-2,5dione (4-maleicanhydridoproton sponge, MAPS) [10]. The maleicanhydrido functionality imparts MAPS lessened basicity with respect to PS [11] and superior properties as MALDI matrix. In detail, MAPS performs well in allowing to detect and analyze small, fragile molecules, otherwise susceptible to undergo degradation under MALDI conditions, thus hampering their detection and quantitation. Moreover, the enhanced vacuum stability of MAPS allows the visualization of tumor onto heterogenous glioma sections by MALDI-MS Imaging based on detection of oncometabolites [12].

The key functionality differentiating MAPS from PS is obviously the maleicanhydrido group, which is prone to react with nucleophiles. At the same time MAPS holds the 1,8-bis(dimethylamino) substituents that are associated to deprotonating activity towards analytes. These groups allow both PS and MAPS to generate anions from acidic analytes, performing what has been named matrix-assisted ionisation/laser desorption (MAILD) 8, 13-14]. One may note, however, that in the case of MAPS the formed nucleophilic anion is potentially reactive towards the maleicanhydrido group.

In order to gain insight into the molecular basis for MAPS behavior we have undertaken a study on the naked ionic species obtained under electrospray ionization (ESI) in the presence of different solvents and simple molecules. These substances are chosen to represent functional groups that may engage interaction with the MAPS matrix. Intermediates thus formed may lay in the path finally yielding the desired analyte ions. The present contribution is focused on revealing and characterizing any adduct possibly formed. To this end ESI of MAPS solutions has been effected in combination with FT-ICR mass spectrometry allowing high resolution mass measurements and ion-molecule reactivity studies [15]. Furthermore, MAPS derived ions have been assayed by IR multiple photon dissociation (IRMPD) spectroscopy, allowing structural characterization based on the matching between experimental and calculated vibrational features [16-21]. Moreover, in this work it is shown that the approach used to gain chemical insight may be beneficial in the development of reactive MALDI-MSI as a promising targeted MSI technique for the visualization of small metabolites such as atropine directly on a tissue section.

\section{Materials and methods}

\section{Chemicals and sample preparation}

MAPS was synthesized in Bielefeld as previously described [10]. The synthetic procedure is easy, not expensive and very little time consuming. One needs only to be careful and work under inert atmosphere. 
MAPS samples should be stored under inert atmosphere to prevent slow degradation to PS. A solution of MAPS was prepared $10^{-3} \mathrm{M}$ in acetonitrile. Sample solutions for ESI analysis were further diluted to $5 \times 10^{-7}$ $M$ in the selected solvent or solvent mixture. Solvents (HPLC-MS grade) and other chemicals (e.g. ammonia and $\mathrm{N}, \mathrm{N}, \mathrm{N}^{\prime}, \mathrm{N}^{\prime}$-tetramethylethylenediamine) were purchased from Sigma-Aldrich (Milan, Italy). Any other additive was used at $10^{-6} \mathrm{M}$ concentration in the solutions for ESI analysis.

\section{Methods}

The sample solutions were directly infused into the ESI source of a quadrupole ion-trap mass spectrometer (Esquire 6000+, Bruker) in Roma. For the Collision Induced Dissociation (CID) experiments, typical conditions were an activation amplitude of $0.25-0.80 \mathrm{~V}$ and activation time of $100 \mathrm{~ms}$. For the IRMPD experiments the ions of interest were mass selected, trapped for 5 to $10 \mathrm{~ms}$ to allow collisional cooling and submitted to irradiation by a tunable OPO/OPA laser pumped by a Nd:Yag laser source for 2 seconds [2223]. The average OPO/OPA laser power was $27 \mathrm{~mJ} /$ pulse delivered at 10 pulse/sec. $\mathrm{A} \mathrm{CO}_{2}$ laser (Universal Laser Systems, Inc., Scottsdale, AZ, USA), synchronized to start $10 \mu \mathrm{s}$ after the OPO/OPA laser, was also employed in order to increase, if needed, the IRMPD signal intensity. In particular a $4 \mathrm{~ms}$ pulse, corresponding to an energy of $520 \mathrm{~mJ}$, was used for the recording of the [MAPS $\left.+\mathrm{NH}_{3}+\mathrm{H}\right]^{+}$IRMPD spectra. This pulse length is verified not to activate the IRMPD process unless coupled with the tunable OPO/OPA IR beam. The IR action spectra are obtained by plotting the photofragmentation yield $R\left(R=-\log \left(I_{p} /\left(I_{p}+\sum I_{f}\right)\right.\right.$, where $I_{p}$ and $\Sigma l_{f}$ are the parent and sum of fragment ion intensity, respectively) as a function of the radiation wavenumber [24].

High resolution mass measurements were performed in Roma on a Bruker BioApex Fourier transform ion cyclotron resonance (FT-ICR) mass spectrometer equipped with an Apollo I ESI source, a 4.7 T superconducting magnet, and a cylindrical infinity cell (Bruker Daltonics, Billerica, MA, USA). The sample solution was infused via a $50 \mathrm{~mm}$ i.d. fused-silica capillary to the ESI source at a rate of $3 \mu \mathrm{L} / \mathrm{min}$ and ions were accumulated in a rf-only hexapole ion guide for $0.8 \mathrm{~s}$. Typical operating conditions were a spray voltage of $4.3 \mathrm{kV}$, capillary to skimmer potential difference $100 \mathrm{~V}$, countercurrent $\mathrm{N}_{2}$ gas at $130^{\circ} \mathrm{C}$. The ions led into the FT-ICR cell at room temperature were chirp excited and detected in direct mode (512 kword time-domain data). Normally, one hundred time-domain data sets were co-added, Hanning apodized, zerofilled once, and subjected to Fourier transform followed by magnitude calculation. The FT-ICR mass spectra were calibrated with respect to ions of known elemental composition. Mass measurements are based on the "monoisotopic" ion (i.e., the species in which all carbons are ${ }^{12} \mathrm{C}$, all oxygens are ${ }^{16} \mathrm{O}$, all nitrogens are ${ }^{14} \mathrm{~N}$, and so on). Mass spectral data were analyzed by the Xmass Analysis software package.

Calculations were performed employing the Gaussian09 rev. D01 package [25]. The whole set of structures presented in the forthcoming sections was optimized at the B3LYP/6-311+G** level of theory [26-27]. Vibrational frequencies and thermodynamic correction to the electronic energy were calculated at the same level. The calculated linear IR spectra presented here are scaled by the 0.957 factor that was found appropriate in previous work employing the same level of theory [28-29].

\section{MALDI-MSI of atropine in Atropa belladonna berries}

Atropa Belladonna berry was sliced by cryo-microtom at $-25^{\circ} \mathrm{C}$ and $\alpha$-methyl cellulose was used as tissue support. Samples were scanned (Plustec optiLab 850, Ahrensburg, Germany) with an image resolution of $2400 \mathrm{dpi}$ and covered with MAPS matrix $(5 \mathrm{mg} / \mathrm{mL}$ in $90 \%(\mathrm{v} / \mathrm{v})$ acetonitrile/chloroform) using the ImagePrepTM device (Bruker Daltonics, Bremen, Germany). The parameters for deposition of MAPS consist in 30 cycles, spray power of $25 \%$, modulation $10 \%$, spray time $1,5 \mathrm{~s}$, incubation time $75 \mathrm{~s}$ and dry time $30 \mathrm{~s}$. 
Mass spectrometric analyses were performed in the reflectron positive mode accelerating potential on a time-of-flight mass spectrometer (Bruker ultrafleXtreme; Bruker Daltonics, Bremen, Germany) with the following parameters: ion source 1 voltage $20.01 \mathrm{kV}$, ion source 2 voltage $17.81 \mathrm{kV}$, reflector 1 voltage $21.25 \mathrm{kV}$, reflector 2 voltage $10.78 \mathrm{kV}$ and lens voltage $8.70 \mathrm{kV}$. The mass spectrometer was equipped with a Smartbeam laser (Nd:YAG $355 \mathrm{~nm}$ ) capable of operating at a repetition rate of $1000 \mathrm{~Hz}$ with optimized delayed extraction time and laser beam size set to small. Laser energy was optimized for signal-to-noise in each preparation. Mass spectral data sets were acquired over a whole section using flex/maging ${ }^{\mathrm{TM}}$ software (Bruker Daltonics, Bremen, Germany) in the $\mathrm{m} / \mathrm{z}$ 400-1000 mass range, with a raster step size of $70 \mu \mathrm{m}$ (10 $\mu \mathrm{m}$ for the high resolution MALDI-MSI), 400 laser shots per spectrum and with a sample rate of $4 \mathrm{GHz}$. After data acquisition, molecular images were reconstituted using the flexlmaging ${ }^{\mathrm{TM}}$ software. Each data set consists of approximately 20000 individual sampling locations, or pixels. The MSI data were normalized by Total Ion Count normalization. Data were normalized using the flex/maging ${ }^{\mathrm{TM}}$ software. For display purposes, data were interpolated and pixel intensities were rescaled in flexlmaging ${ }^{\mathrm{TM}}$ to utilize the entire dynamic range. These experiments were performed in Bielefeld.

\section{Results and discussion}

\section{ESI-FT-ICR mass analysis of MAPS. Formation of protonated MAPS adducts.}

Fig. 1 shows the mass spectrum recorded when a dilute solution of MAPS in acetonitrile-water 5:1 (v:v) is submitted to ESI. The expanded mass spectrum, not limited to the range of interest, is presented in Fig. S1 in the Electronic Supplementary Material (ESM). Protonated MAPS at nominal $m / z 311$ is accompanied by a significantly intense signal at $\mathrm{m} / \mathrm{z} 329$ which may be assigned to an adduct of protonated MAPS with water. A minor signal at $m / z 314$ may be attributed to fragmentation of the water adduct by methyl loss. The measured mass of 329.14986 Da for the protonated water adduct of MAPS is within the estimated error of $\pm 5 \mathrm{ppm}$ when compared with the calculated mass of $329.14958 \mathrm{Da}$ for the $\mathrm{C}_{18} \mathrm{H}_{21} \mathrm{~N}_{2} \mathrm{O}_{4}$ formula. For comparison purposes, the experimental mass of protonated MAPS is measured equal to $311.13934 \mathrm{Da}$ (calculated mass for the $\mathrm{C}_{18} \mathrm{H}_{19} \mathrm{~N}_{2} \mathrm{O}_{3}$ formula $=311.13902 \mathrm{Da}$ ). 


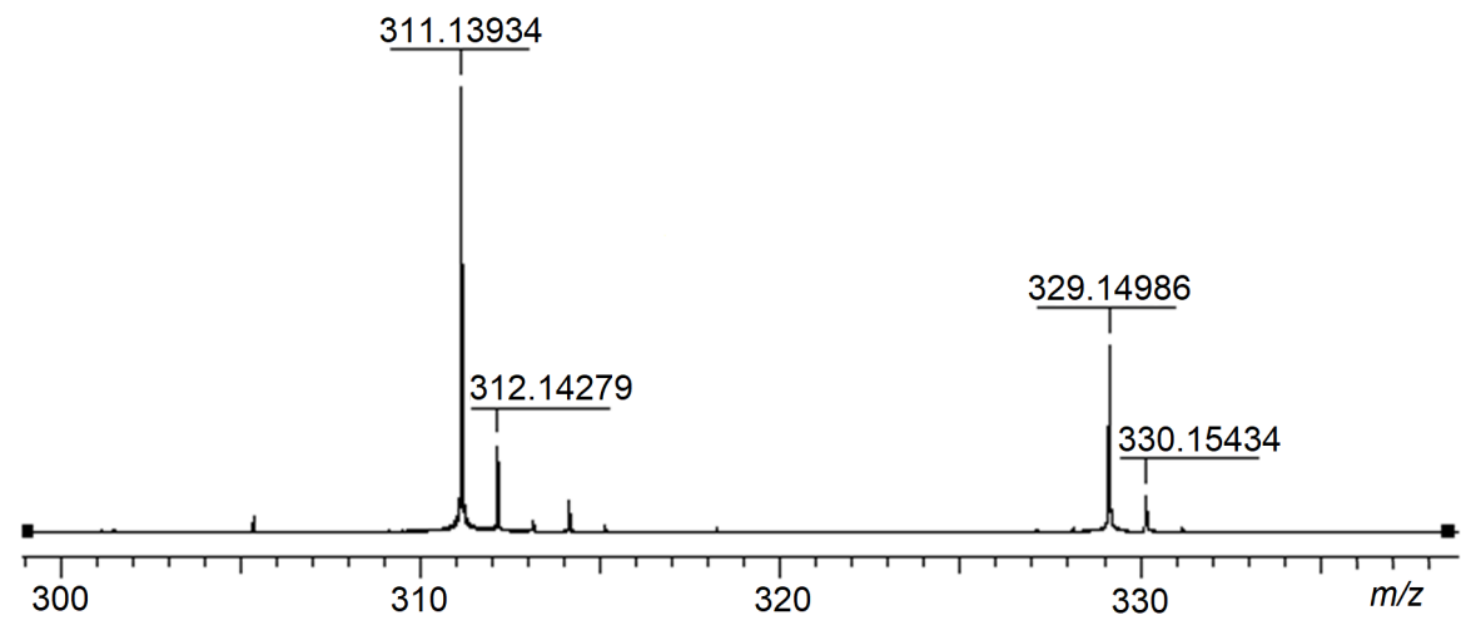

Fig. 1 ESI-FT-ICR mass spectrum of an acetonitrile/water (5:1 v/v) solution of MAPS showing the $m / z$ values for $[\mathrm{MAPS}+\mathrm{H}]^{+}$and $\left[\mathrm{MAPS}+\mathrm{H}+\mathrm{H}_{2} \mathrm{O}\right]^{+}$ions

In order to ascertain whether addition of solvent molecules (water is reactive but acetonitrile is not) is a general behavior of MAPS, ESI of an acetonitrile/methanol solution was tested and found to deliver ions at $\mathrm{m} / \mathrm{z} 343$, corresponding to [MAPS $\left.+\mathrm{H}+\mathrm{CH}_{3} \mathrm{OH}\right]^{+}$. A distinct tendency towards yielding adducts with selected solvents upon ESI is thus displayed by MAPS, seemingly requiring the presence of a mobile proton, though. In fact acetonitrile, endowed with comparable if not superior solvating ability of positively charged species, is not effective in yielding an adduct with protonated MAPS.

Adduct formation may conceivably occur also as a gas phase process undergone by protonated MAPS in the presence of volatile nucleophilic molecules. The reactivity of $[\mathrm{MAPS}+\mathrm{H}]^{+}$ions was thus assayed in the FT-ICR cell allowing the ESI-formed ions at $m / z 311$ to react with a neutral admitted at controlled pressure in the range of $10^{-8}-10^{-7}$ mbar. However, even at highest pressure, both water and methanol proved to be unreactive and a strong base/nucleophile such as 4-methylpyridine, with a proton affinity (PA) equal to 947 $\mathrm{kJ} / \mathrm{mol}[30]$, was equally unreactive.

This evidence leads us to discard the gas phase as the likely medium where protonated MAPS adducts may be formed in either ESI or possibly also MALDI processes.

Accurate mass analysis alone, while confirming elemental composition of the sampled ions, does not provide structural information, which was then sought by CID experiments and IRMPD spectroscopy.

\section{CID assay of protonated MAPS adduct ions}

The CID fragmentation pattern of $[\mathrm{MAPS}+\mathrm{H}]^{+}$ions has been inspected and the one of protonated PS, $[\mathrm{PS}+\mathrm{H}]^{+}$ions at $m / z 215$, is also reported for comparison purposes. As shown in Fig. 2, both species present loss of methyl as major primary dissociation path. In contrast, $\mathrm{CID}$ of $\left[\mathrm{MAPS}+\mathrm{H}_{+} \mathrm{H}_{2} \mathrm{O}\right]^{+}$displays loss of $\mathrm{CO}_{2}$ as major primary process accompanied by loss of water, albeit to a minor extent, forming ions at $\mathrm{m} / \mathrm{z} 285$ and 311 , respectively. 

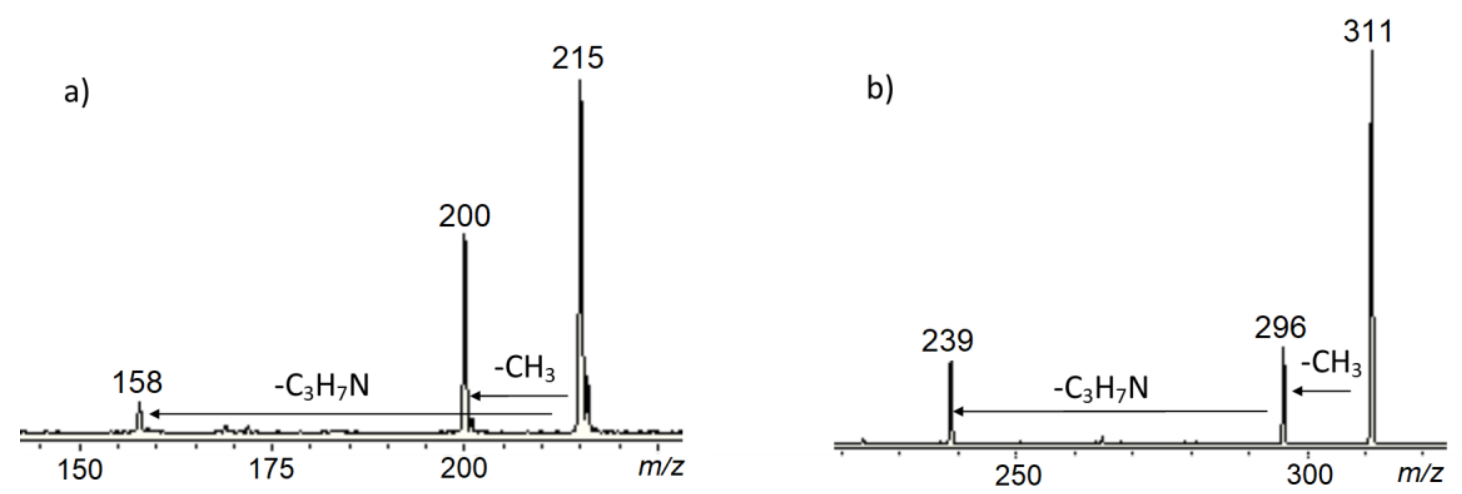

c)

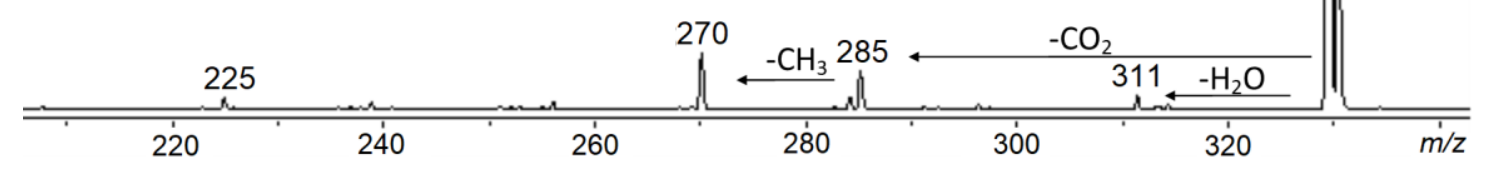

Fig. $2 \mathrm{CID}$ mass spectra of mass isolated a) [PS+H] ${ }^{+}(\mathrm{m} / \mathrm{z} 215)$, b) [MAPS $\left.+\mathrm{H}\right]^{+}(\mathrm{m} / \mathrm{z} 311)$ and c) [MAPS $+\mathrm{H}+$ $\left.\mathrm{H}_{2} \mathrm{O}\right]^{+}(m / z$ 329). Main channels of neutral loss are reported.

The rather minor cleavage of water speaks against a non-covalent complex of protonated MAPS solvated by a water molecule, because of the expected easy water loss. The presence of a non-covalent complex engaging the protonated dimethylamino group is also disproven because a $\left[\mathrm{PS}+\mathrm{H}_{+}+\mathrm{H}_{2} \mathrm{O}\right]^{+}$complex is in fact not detected under exactly similar conditions from ESI of a solution containing both PS and MAPS. So, it may be concluded that it is the maleicanhydrido functionality to be involved in covalent adduct formation. The loss of $\mathrm{CO}_{2}$ is consistent with the formation of a covalent adduct where water has hydrolyzed the maleicanhydrido moiety (Scheme $1, \mathrm{MH}=\mathrm{H}_{2} \mathrm{O}$ ). However, the minor presence of water loss $(\mathrm{m} / \mathrm{z} 311)$ from [MAPS $\left.+\mathrm{H}_{+} \mathrm{H}_{2} \mathrm{O}\right]^{+}$ion does not dismiss that a fraction of the sampled species may be represented by a noncovalent water adduct, presumably with the water oxygen atom coordinated with the charged proton shared between the two dimethylamino groups. 


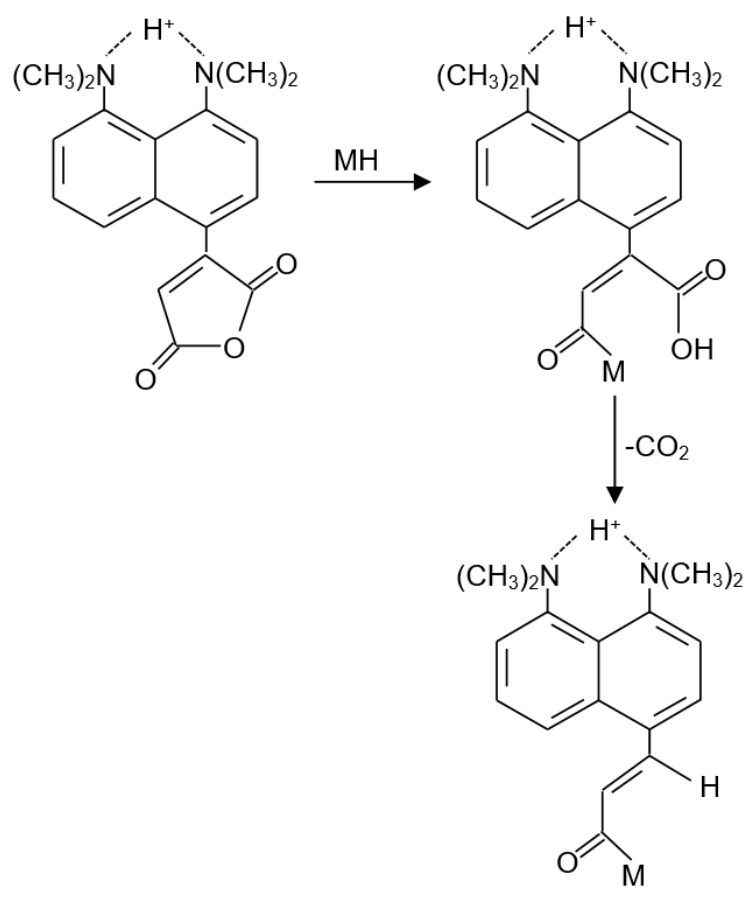

Scheme 1 Reaction path showing addition of $\mathrm{MH}$ onto the maleicanhydrido group of MAPS, followed by $\mathrm{CO}_{2}$ loss.

As stated in the previous paragraph, ESI of MAPS in acetonitrile/methanol yields MAPS adducts as shown in the mass spectrum reported in Fig. 3a. In this case cationization is achieved not only by protonation but also by alkali metal $\left(\mathrm{Na}^{+}, \mathrm{K}^{+}\right)$attachment.

The $\mathrm{CID}$ mass spectrum of $\left[\mathrm{MAPS}+\mathrm{H}+\mathrm{CH}_{3} \mathrm{OH}\right]^{+}$at $\mathrm{m} / \mathrm{z} 343$ shown in Fig. $3 \mathrm{~b}$ is characterized by more extensive fragmentation than in the same experiment involving [MAPS $\left.+\mathrm{H}^{+} \mathrm{H}_{2} \mathrm{O}\right]^{+}$. Anyway, a comparable behavior can be recognized, namely an important loss of $\mathrm{CO}_{2}(\mathrm{~m} / \mathrm{z} 299)$ followed by $\mathrm{CH}_{3}$ cleavage $(\mathrm{m} / \mathrm{z} 284)$ and subsequent dissociations, and a minor, but significant, fragmentation with loss of methanol as neutral ( $\mathrm{m} / \mathrm{z}$ 311). Therefore, the CID experiment is in agreement with the presence of a covalent adduct also in this case. The main structural difference will be the formation of a methyl ester instead of the carboxylic group that is formed in the maleicanhydrido unit upon reaction with methanol rather than with water (Scheme 1, $\mathrm{MH}=\mathrm{CH}_{3} \mathrm{OH}$ ). 

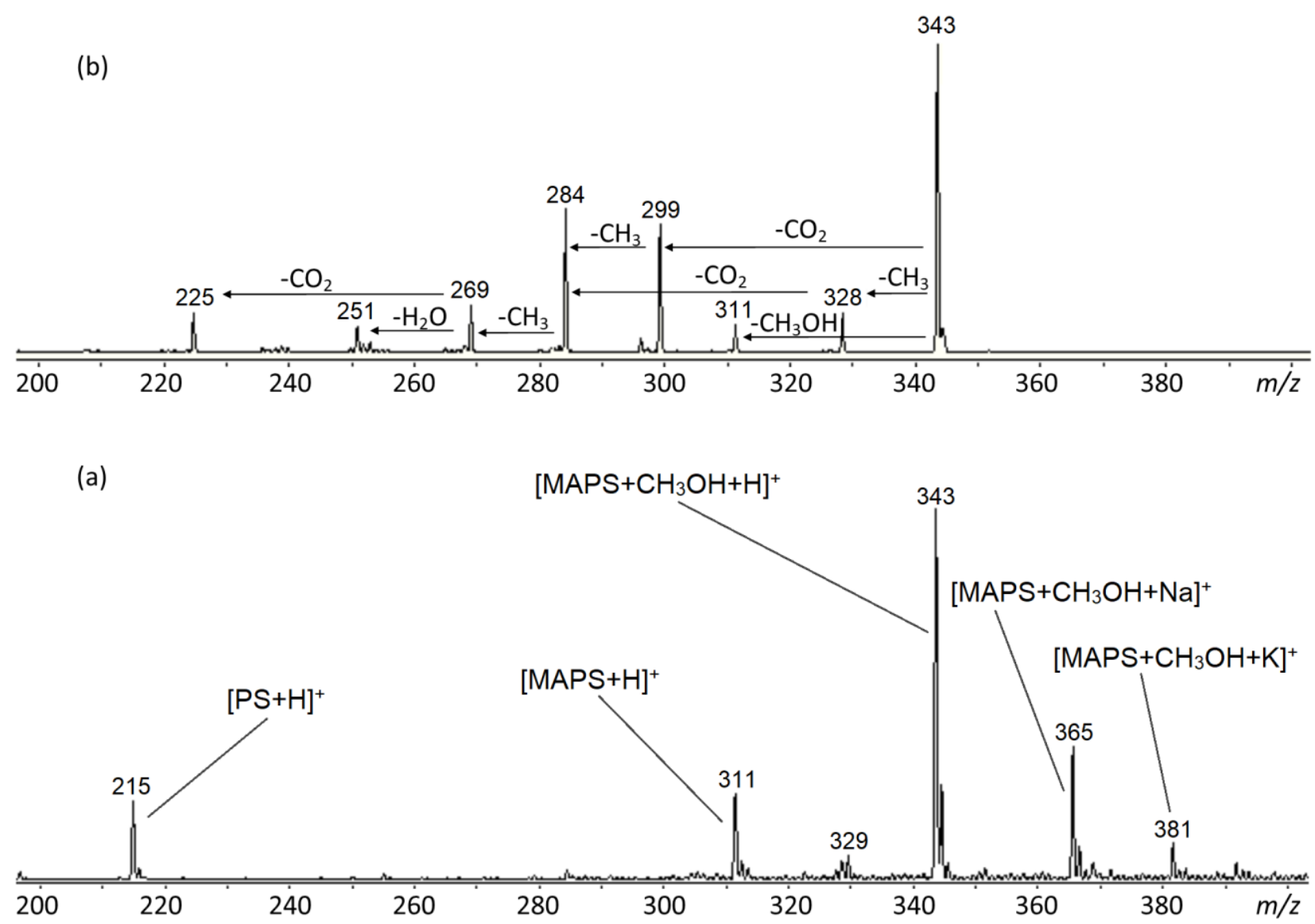

Fig. 3 (a) ESI mass spectrum of an acetonitrile/methanol (5:1 v/v) solution of MAPS; (b) CID mass spectrum of the $\left[\mathrm{MAPS}+\mathrm{H}+\mathrm{CH}_{3} \mathrm{OH}\right]^{+}$ion at $m / z 343$

A stronger nucleophile, namely ammonia, added in the acetonitrile solution in the presence of MAPS reacts extensively to form [MAPS $\left.+\mathrm{H}+\mathrm{NH}_{3}\right]^{+}$ions at $\mathrm{m} / \mathrm{z}$ 328. The ammonia adduct is not formed with protonated PS, also present in the solution sampled by ESI to give the mass spectrum shown in Fig. 4a. The ammonia adduct accounts for nearly all MAPS derived ions while protonated MAPS accounts for only a small fraction of the ion abundance. Dissociation paths reproduce well the ones observed from the water and the methanol adducts, indicating common structural features (Fig. 4b). 

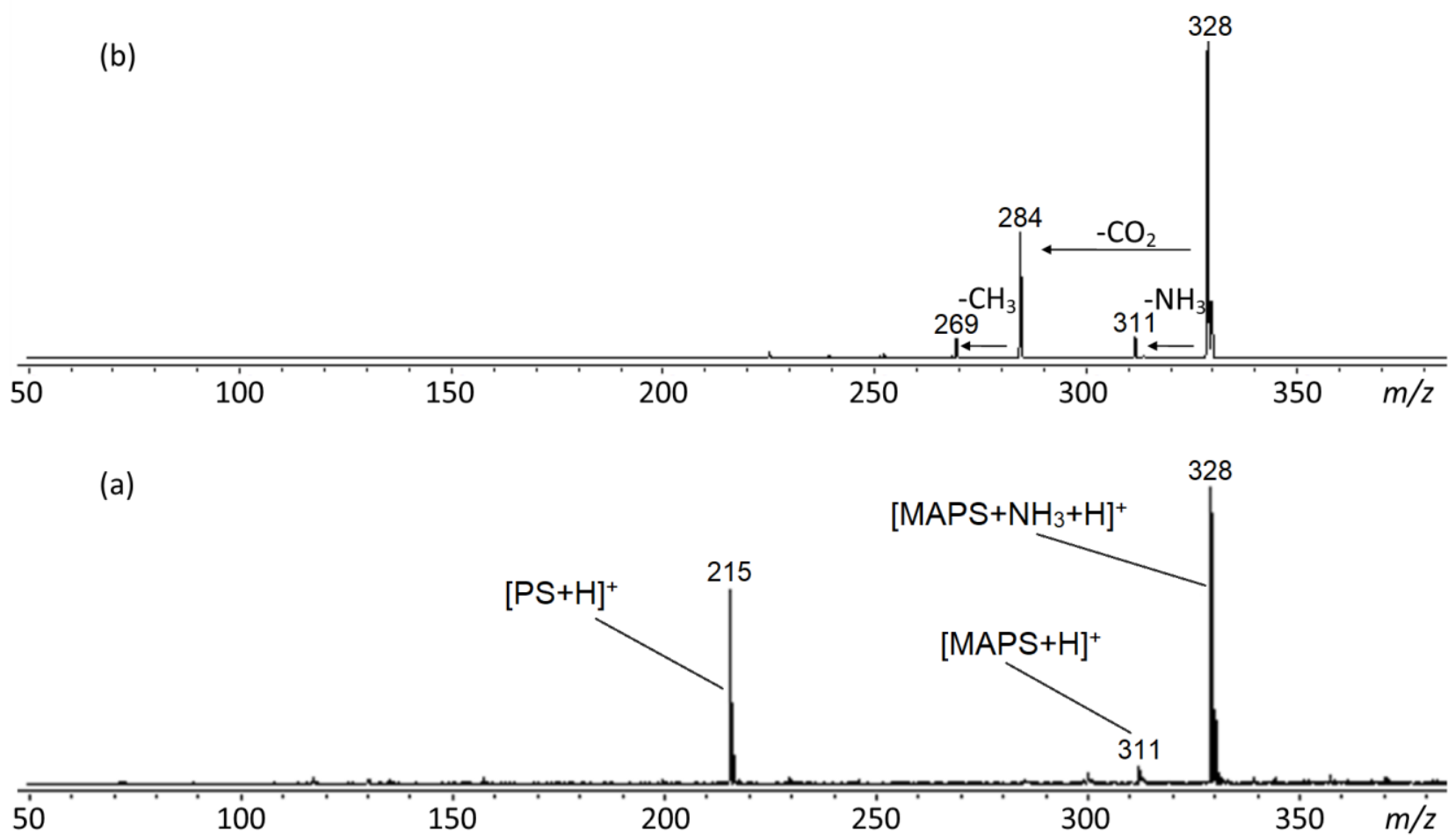

Fig. 4 (a) ESI mass spectrum of the solution of MAPS and PS in the presence of ammonia; (b) CID mass spectrum of the $\left[\mathrm{MAPS}+\mathrm{H}+\mathrm{NH}_{3}\right]^{+}$ion at $m / z 328$.

\section{IRMPD assay of protonated MAPS adduct ions}

The CID results concur in supporting a covalent structure for protonated MAPS adducts with water, methanol and ammonia. However, a more reliable structural probe has been sought by resorting to IRMPD spectroscopy in the wavenumber range of $3100-3700 \mathrm{~cm}^{-1}$ where $\mathrm{NH}$ and $\mathrm{OH}$ stretching modes are expected to be active. The IRMPD spectrum of [MAPS $\left.+\mathrm{H}^{+} \mathrm{H}_{2} \mathrm{O}\right]^{+}$ions is plotted in Fig. $5 \mathrm{a}$. It shows a distinct signal at $3563 \mathrm{~cm}^{-1}$. In order to assign this band and derive structural information, the experimental spectrum is compared with the calculated IR spectra of candidate isomers. Thus panels $b$ and $c$ in Fig. 5 show the IR spectra of the optimized geometries for the non-covalent (MAPS-H2O_1) and covalently bound (MAPS-H2O_2) isomers, respectively. The calculated frequencies of MAPS-H2O_1 and MAPS-H2O_2 are also listed in Table S1 in the ESM. For comparison purposes, calculations have also been performed on the non-covalent adduct of proton-sponge with water, although the $\left[\mathrm{PS}+\mathrm{H}_{+} \mathrm{H}_{2} \mathrm{O}\right]^{+}$complex is not experimentally observed. The optimized structure (PS-H2O_1) is reported in Fig. S2 in the ESM and the vibrational modes are also reported Table S1. The comparative evaluation of IR features characterizing MAPS-H2O_1 and PSH2O_1 show a negligible influence of the maleicanhydrido group on the vibrational modes of the non- 
covalently bound water. The observed insignificant variation of both frequencies and intensities for $\mathrm{OH}$ stretching modes of non covalently bound water is likely due to the remote interaction with the additional ring substitutent. In fact, in both MAPS-H2O_1 and PS-H2O_1 the water molecule interacts with the proton shared by the two dimethylamino groups, on the opposite side of the naphthalene plane with respect to the binding site of the maleicanhydrido substituent. The experimental band in Fig. 5a is well matched by the $\mathrm{OH}$ stretch of the carboxylic group generated by the hydrolysis of the maleicanhydrido moiety, specifically the one in cis conformation in MAPS-H2O_2 calculated at $3580 \mathrm{~cm}^{-1}$. The IR spectrum obtained for this isomer presents also a signal at $3303 \mathrm{~cm}^{-1}$, corresponding to the $\mathrm{OH}$ stretch of the second hydroxyl group. This group is however involved in a hydrogen bond with the carbonyl oxygen of the second neighboring carboxylic moiety. The failure of IRMPD to reveal this signature is traced to the hydrogen bonding motif, that is known to impart pronounced anharmonic character and broadening of the absorption. The combined effects may render the associated mode hardly detectable by IRMPD, as well documented in several instances [31-34]. It should be noted how the comparison between experiment and theory points to the presence, in the sampled gas-phase population, of a major contribution of the covalently bound isomer MAPS-H2O_2, although MAPS-H2O_1 is energetically favored. However, it has been reported in several studies characterizing ions delivered by ESI-MS, that isomers lying higher in energy as isolated species can be preferentially generated in solution, transferred to the gas phase and kinetically trapped in local minima by high barriers for their interconversion to the most stable gaseous isomer [3539]. Thus, the reported dichotomy between the thermodynamic stability and experimental evidence is not surprising, considering that the two isomers MAPS-H2O_1 and MAPS-H2O_2 are not likely to interconvert in the gas-phase. Thus, the gathered evidence suggests we are sampling and assaying the species that were previously formed in solution. 


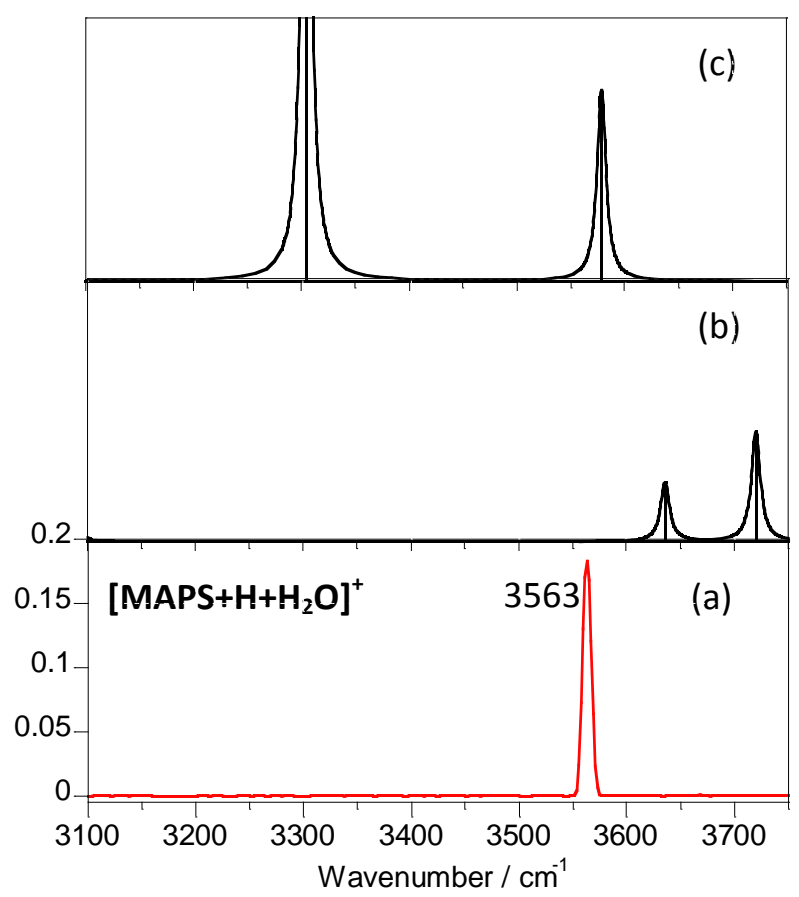

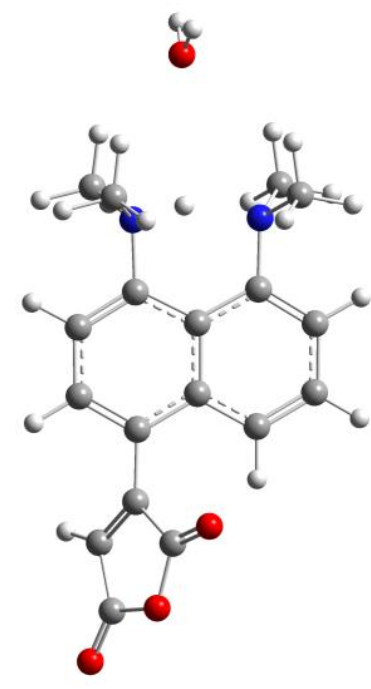

MAPS-H2O_1

$\mathrm{G}_{\mathrm{rel}}=0.0 \mathrm{~kJ} / \mathrm{mol}$

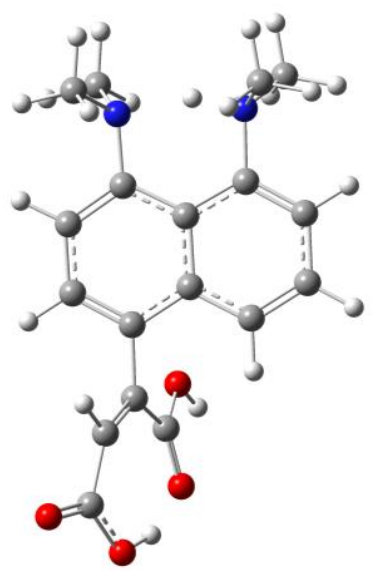

MAPS-H2O_2

(covalent adduct)

$\mathrm{G}_{\mathrm{rel}}=15.7 \mathrm{~kJ} / \mathrm{mol}$

Fig. 5 (a) IRMDP spectrum of [MAPS $\left.+\mathrm{H}^{+} \mathrm{H}_{2} \mathrm{O}\right]^{+}$compared to calculated spectra of MAPS-H2O_1 (b) and MAPS-H2O_2 (c)

The IRMPD fragments reflect the dissociation path observed at low $\mathrm{CID}$ energy. The relative abundances of the three major products involving loss of $\mathrm{CO}_{2}, \mathrm{CO}_{2}+\mathrm{CH}_{3}$, and $\mathrm{H}_{2} \mathrm{O}$, are plotted in Fig. $\mathrm{S} 3$ (in the Electronic Supplementary Material, ESM). Interestingly, both water loss and cleavage of $\mathrm{CO}_{2}$ share the same profile, indicating a common precursor. Thus, the possible supposition that dissociation of water might be associated to the presence of a non-covalent adduct is in fact disproven.

The methanol adduct [MAPS $\left.+\mathrm{H}+\mathrm{CH}_{3} \mathrm{OH}\right]^{+}$has also been assayed by IRMPD spectroscopy. Perhaps disappointingly, no signal is observed in the inspected $3100-3700 \mathrm{~cm}^{-1}$ range. However, this finding validates the attribution of the signal at $3563 \mathrm{~cm}^{-1}$ in the IRMPD spectrum of [MAPS $\left.+\mathrm{H}_{+} \mathrm{H}_{2} \mathrm{O}\right]^{+}$in Figure $5 \mathrm{a}$, because the free hydroxyl, not involved in hydrogen bonding, is now methylated and therefore the corresponding $\mathrm{OH}$ stretch is missing.

Finally, the IRMPD spectrum of the ammonia adduct, [MAPS $\left.+\mathrm{H}+\mathrm{NH}_{3}\right]^{+}$, is reported in Fig. 6 a. 

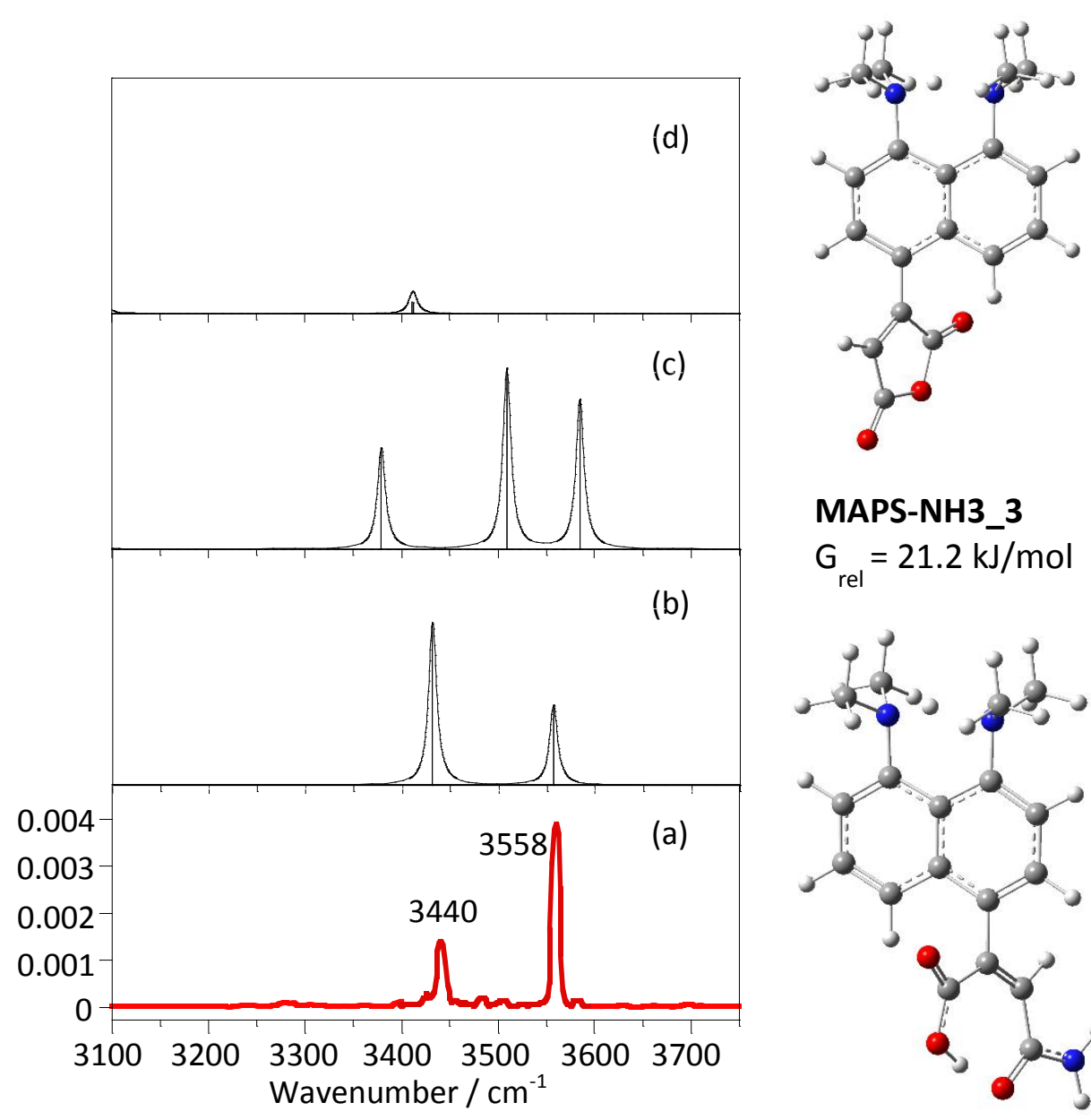

MAPS-NH3_3 $\mathrm{G}_{\mathrm{rel}}=21.2 \mathrm{~kJ} / \mathrm{mol}$

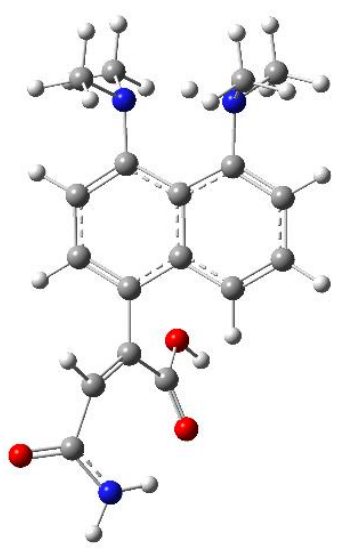

MAPS-NH3_2 $\mathrm{G}_{\mathrm{rel}}=9.8 \mathrm{~kJ} / \mathrm{mol}$

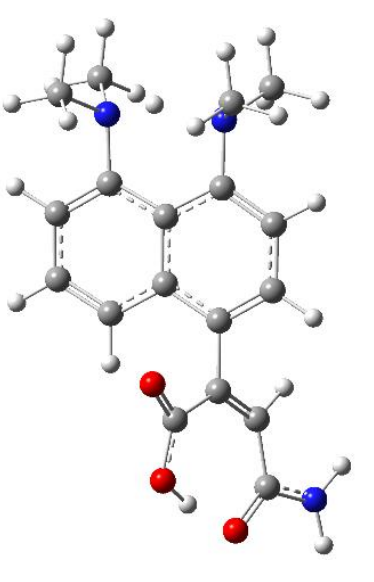

MAPS-NH3_1

$\mathrm{G}_{\mathrm{rel}}=0.0 \mathrm{~kJ} / \mathrm{mol}$

Fig. 6 IRMPD spectrum of $\left[\mathrm{MAPS}+\mathrm{H}+\mathrm{NH}_{3}\right]^{+}$(a) compared to calculated IR spectra for MAPS-NH3_1 (b), MAPS-NH3_2 (c) and MAPS-NH3_3 (d)

The photofragmentation spectrum of $\left[\mathrm{MAPS}+\mathrm{H}+\mathrm{NH}_{3}\right]^{+}$shows two signals, in particular the most intense band appears at $3558 \mathrm{~cm}^{-1}$, while a smaller signal is present at $3440 \mathrm{~cm}^{-1}$. As usual, to gain insight into the experimental spectrum, candidate structures for the sampled ion were explored and the optimized geometries of MAPS-NH3_1, MAPS-NH3_2 and MAPS-NH3_3 isomers are shown in Fig. 6 together with the respective IR spectra, while the IR frequencies and intensities are reported in Table S2 in the ESM. The experimental features are well accounted for by the calculated vibrational modes of the lowest lying covalently bound conformer MAPS_NH3_1. In fact, the computed resonances at 3557 and $3431 \mathrm{~cm}^{-1}$, corresponding respectively to the asymmetric and symmetric stretching modes of the amido $\mathrm{NH}_{2}$ moiety, well reproduce the experimental signals at 3558 and $3440 \mathrm{~cm}^{-1}$ of the [MAPS $\left.+\mathrm{H}+\mathrm{NH}_{3}\right]^{+}$IRMPD spectrum, 
suggesting the covalent adduct between MAPS and ammonia to have a major role in the sampled gasphase population.

\section{Adducts of protonated MAPS with selected biologically active molecules}

The tendency of protonated MAPS to form adducts in acetonitrile solution, which are then delivered by ESI, has been tested with selected molecules of biological interest (M), such as amino acids and compounds bearing amino or imino nitrogen atoms. The formation of adducts is not always observed. Table 1 shows a list of the tested compounds together with the respective values of proton affinity and gas phase basicity from the NIST database [30]. Whenever an adduct is formed, sampling by CID reveals the known primary fragmentation channels, yielding major $\mathrm{CO}_{2}$ loss and minor $\mathrm{M}$ loss (Equation 1). It is reasonable to infer that in all cases a covalent adduct is formed. Only in one case has loss of $\mathrm{MH}^{+}$been observed, which occurs with the most basic among the sampled $\mathrm{M}$, namely histidine.

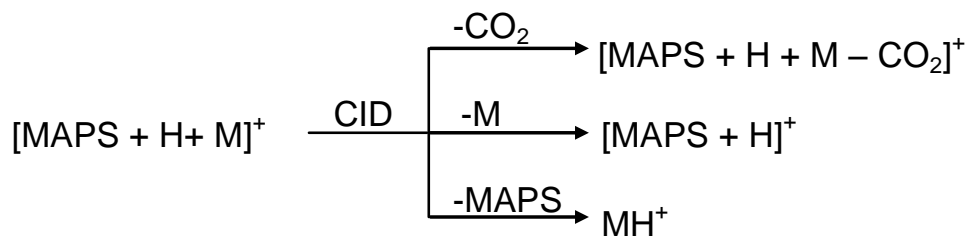

Under the assumption that the fragmentation along the two channels leading to $[\mathrm{MAPS}+\mathrm{H}]^{+}$and to $\mathrm{MH}^{+}$is reflecting the relative basicity of the two partners, M and MAPS [40-41], one may derive an estimated gas phase basicity of MAPS comprised between the one of histidine and that of PS, likely close to $962 \mathrm{~kJ} / \mathrm{mol}$. The electron withdrawing effect of the maleicanhydrido group is responsible for the lower basicity of MAPS relative to PS. The reaction of histidine poses some question about the attacking nitrogen atom which could belong either to the alfa amino group or to the imidazole ring. However, 4-methylimidazole, representing the histidine side group, does not add to protonated MAPS under the selected conditions in acetonitrile solvent. In contrast, valine is reactive, thus indicating that the amino group is in fact acting as nucleophile. The results summarized in Table 1 indicate that basicity is not the only factor in determining the outcome of adduct formation with protonated MAPS. The common feature of reactive $M$ is rather the presence of a mobile proton on the attacking nitrogen atom. This point may be explained by the required protonation of the cleaving carboxylate, which is not assisted in the aprotic solvent. The ensuing zwitterionic intermediate is not likely to be formed in the acetonitrile environment. 
Table 1 Adduct formation between protonated MAPS and selected molecules (M)

$\begin{array}{llll}\mathrm{M} & \mathrm{PA}^{\mathrm{b}} & \mathrm{GB}^{\mathrm{b}} & {[\mathrm{MAPS}+\mathrm{H}+\mathrm{M}]^{+}} \\ \text {Pyridine } & 930 & 898 & \text { no } \\ \text { Piperidine } & 954 & 921 & \text { yes } \\ \text { 4-methylimidazole } & 953 & 921 & \text { no } \\ \mathrm{N}, \mathrm{N}, \mathrm{N}^{\prime}, \mathrm{N}^{\prime} \text {-tetramethylethylenediamine } & 1013 & 971 & \text { no } \\ \text { Valine } & 911 & 877 & \text { yes } \\ \text { Histidine } & 1000 & 962 & \text { yes } \\ \text { PS } & 1028 & 996 & \text { no }\end{array}$

${ }^{\text {a }}$ Solutions containing MAPS and M in equimolar amount in acetonitrile were sampled by ESI in positive ion mode.

${ }^{\mathrm{b}}$ Values in $\mathrm{kJ} / \mathrm{mol}$ from Lias et al.[30]

The capability of MAPS to generate adducts with biologically important species containing nucleophilic groups has also been tested with atropine, a natural compound well known for its ability to antagonize the muscarinic receptor. The structure of this species, reported in the inset in Fig. 7, shows the presence of an alcoholic group, that can possibly drive the formation of the covalent adduct. Instead, the ternary amino moiety, also present in the atropine molecule, should not be able to react with the anhydrido moiety of MAPS due to the lack of a mobile proton, as outlined in the previous paragraph. An adduct corresponding to [MAPS+H+Atropine] ${ }^{+}$is in fact observed at $m / z 600$. Fig. 7 displays the fragmentation spectrum obtained from [MAPS+H+Atropine $]^{+}$operating under CID conditions. 


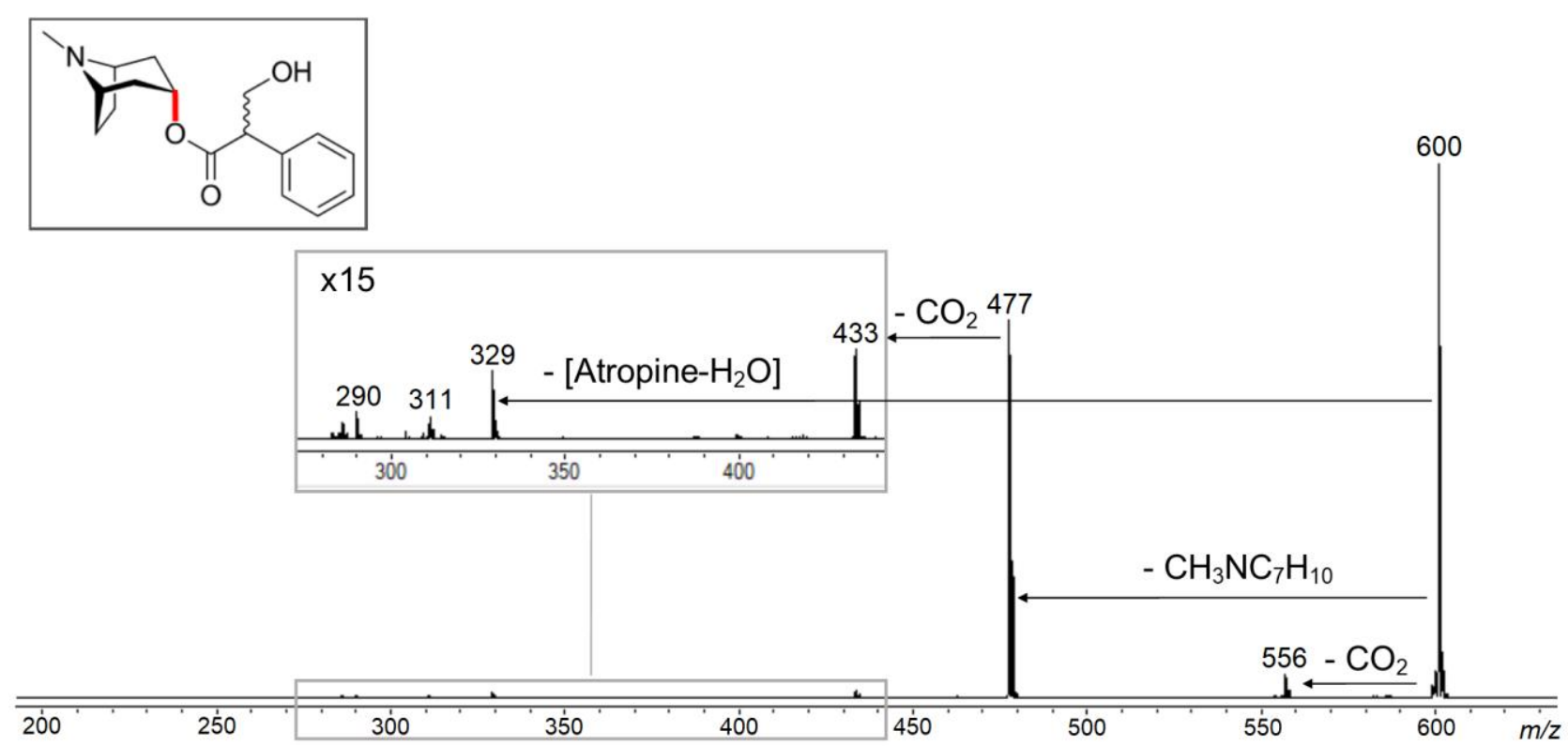

Fig. $7 \mathrm{CID}$ mass spectrum of the [MAPS $+\mathrm{H}+$ Atropine] $^{+}$ion at $m / z 600$. The top-left corner inset displays the structure of neutral atropine. The bond cleaved in the loss of $\mathrm{CH}_{3} \mathrm{NC}_{7} \mathrm{H}_{10}$ from $\mathrm{m} / z 600$ is marked in red.

The fragmentation pattern clearly shows that a covalent protonated adduct of atropine with MAPS was isolated. In fact, the product ion at $\mathrm{m} / \mathrm{z} 556$ is obtained by the common loss of $\mathrm{CO}_{2}$, a diagnostic feature of nucleophilic attack at the anhydrido group. The second, most abundant dissociation product at $\mathrm{m} / \mathrm{z} 477$ involves a formal loss of dehydrated tropine, occurring by cleavage of the ester bond (highlighted in red in the atropine structure in Fig. 7), once again pointing to the fragmentation of a covalently bound adduct, likely formed by the alcoholic group of atropine attacking the maleic anhydrido group. In the event of a non-covalent proton bound heterodimer of atropine and MAPS one should expect protonated MAPS and/or protonated atropine as dissociation fragments at $\mathrm{m} / \mathrm{z} 311$ and $\mathrm{m} / \mathrm{z} 290$, respectively. Indeed, weak signals are observed (see Fig. 7), although their intensity is negligible when compared with the major dissociation products. The presence of both $\mathrm{m} / \mathrm{z} 290$ and $\mathrm{m} / \mathrm{z} 311$ fragments in comparable abundance suggests a similar gas phase basicity of MAPS and atropine, therefore both close to ca. $962 \mathrm{~kJ} \mathrm{~mol}^{-1}$. To conclude, atropine may be expected to be particularly prone to form covalently bound ionic adducts with MAPS, which should behave as a convenient reactive MALDI matrix to reveal and map the distribution of atropine in biological tissues.

\section{Adduct formation as application in MALDI-Mass Spectrometry Imaging}

The notion that MAPS could form a covalent adduct with atropine was applied as proof of concept in MALDI-MSI for localization of atropine in Atropa belladonna berry. In this regard, it is important to mention that the localization of secondary metabolites with relevant biological activity in plant tissue is of great interest because it contributes to state of art methods in plant physiology. For example, Atmosphere Pressure (AP) MALDI-MSI was performed to image tropine alkaloids e.g. scopolamine and derivatives, in 
Duboisia myoporoides $\mathrm{R}$. $\mathrm{Br}$. at different time giving rise to a comprehensive overview of biosynthesis, flow and accumulation of alkaloids from roots to leaves [42]. Despite that, the detection of several metabolites directly on plant tissues by MALDI-MSI is still a challenging task due to the sample preparation, a crucial step for the on-tissue preservation of metabolites [43]. Localization of atropine in Atropa belladonna berry was chosen for two main reasons: 1) atropine contains an alcoholic group in the molecular structure susceptible to display and be revealed via adduct formation with MAPS and 2) it is already known that atropine is mainly localized in the seeds of Atropa belladonna berries [44] (panel (a) in Fig. 8).

Fig. 8a clearly confirms localization of atropine mainly in the seeds, when viewing the ionic map at both $\mathrm{m} / \mathrm{z}$ 600.4 and $m / z$ 598.4. Moreover, hardly any spatial signatures of these ions were observed in the pericarp regions as confirmed by comparing the average mass spectra of seed and pericarp shown in Fig. 8b (mass spectra in wider $\mathrm{m} / \mathrm{z}$ range are depicted in Fig. S4). The actual occurrence of on-tissue derivatization of atropine was confirmed with a dried droplet experiment, performing MALDI-MS of a mixture containing only MAPS and atropine. The resulting mass spectrum, reported in Fig. S5, confirms the major ions appearing at $m / z 600.4$ and $m / z 598.4$ in the MALDI mass spectrum of the seed region (Fig. $8 \mathrm{~b}$ ). It is worth noting that the ion at $\mathrm{m} / \mathrm{z} 598.4$, corresponding to [MAPS-H+Atropine] ${ }^{+}$, was not observed in the ESI-MS experiment described in the previous paragraph. This observation suggests multiple paths leading to adduct ion formation during the MALDI process. Indeed, an important event in ion formation by the MALDI process is UV-absorption by the matrix [45], which triggers photo-induced phenomena (e.g. electron and proton transfer) promoting ionization of matrix [46]. As observed in the mass spectrum of MAPS obtained under MALDI condition and reported in Fig. S6, MAPS is found to yield in fact two ionic species at $\mathrm{m} / \mathrm{z} 309.1$ and 311.1, assigned to [MAPS-H] ${ }^{+}$and $[\mathrm{MAPS}+\mathrm{H}]^{+}$, respectively. Their formation likely involves the 1,8-bis-dimethylamino groups of the proton sponge moiety. The process is depicted in Scheme 2. 
(a)

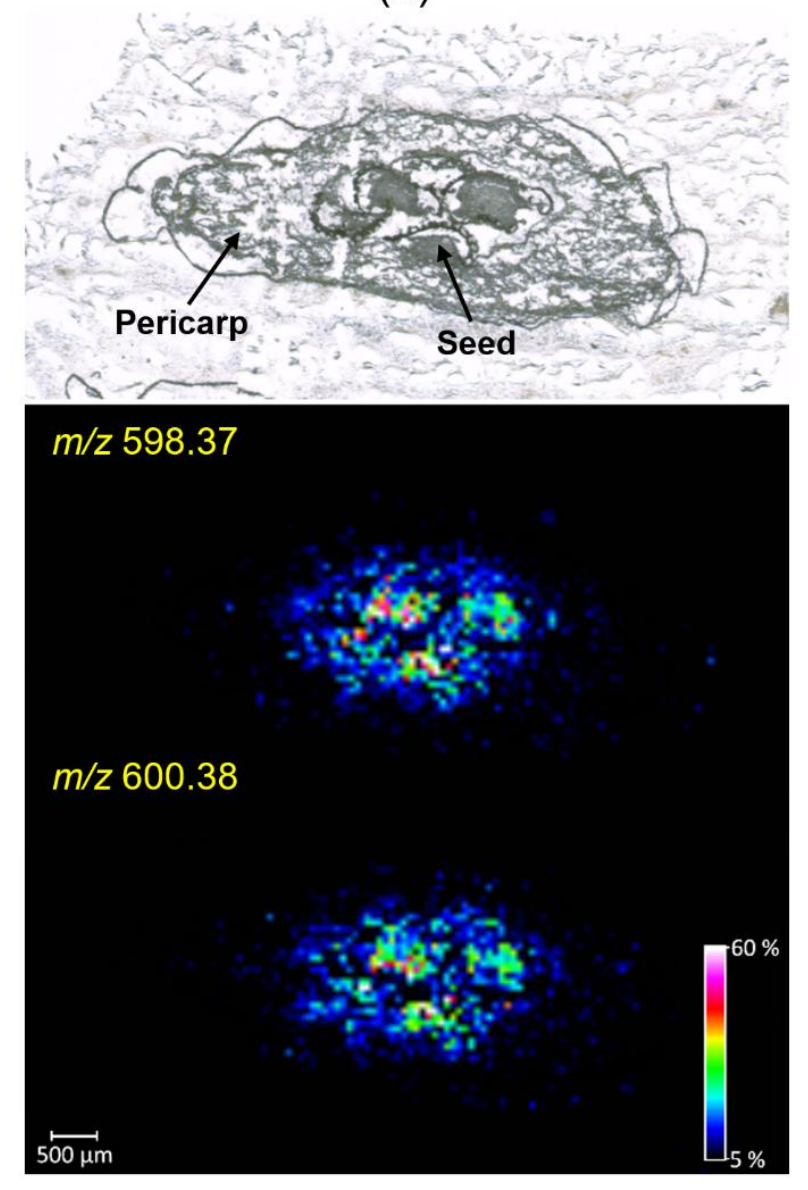

(b)

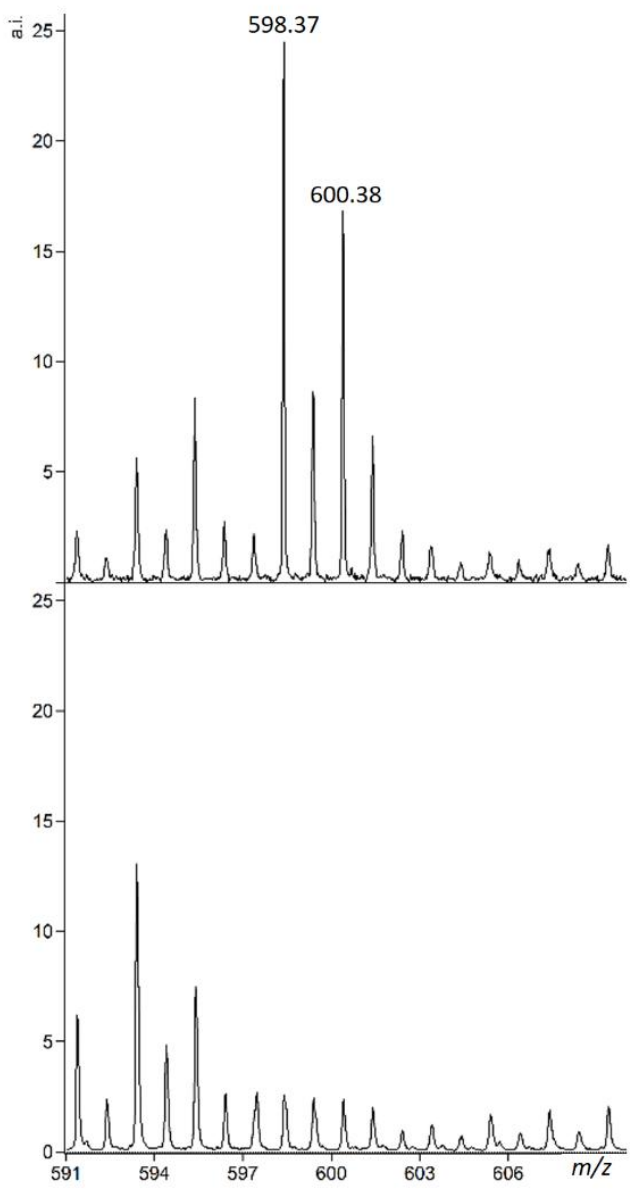

Fig. 8 MALDI-MSI of matrix-atropine adduct onto a section of Atropa belladonna berry. (a) Optical picture depicting a tissue slice of an Atropa Belladonna berry containing seeds and pericarp (marked by the arrows) is compared with the spatial signatures of the ions at $\mathrm{m} / \mathrm{z} 598.4$ [MAPS-H+Atropine] $^{+}$(red) and 600.4 [MAPS+H+Atropine] $^{+}$(green). (b) Excerpts of overall average mass spectra of seed region (top) and of pericarp region (bottom). 

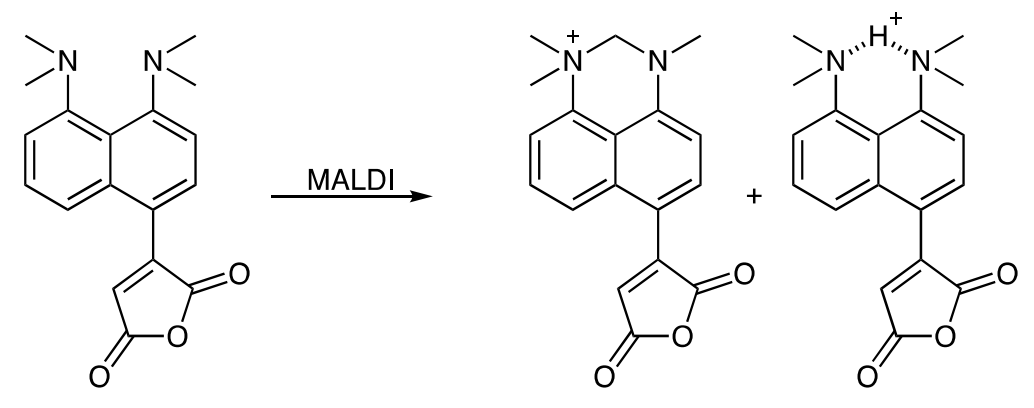

Scheme 2 Ionization of MAPS following the MALDI process. The photoreaction yields two positive ions, [MAPS-H] $^{+}$and [MAPS $\left.+\mathrm{H}\right]^{+}$, at $\mathrm{m} / \mathrm{z} 309$ and 311, respectively. The tentative structure for [MAPS-H] ${ }^{+}$, shown as the first species on the product side, is likely favored with respect to the alternative one presenting the ammonium ion on the same ring hosting the electron-withdrawing maleicanhydrido group.

Formation of [MAPS-H] $]^{+}$finds a counterpart in the already documented process verified in MALDI of PS in which hydrogen atom transfer from ionized PS is proposed to activate an intramolecular cyclization leading to a stable 1,1,3-trimethyl-2,3-dihydropirimidinium ion, $[\mathrm{PS}-\mathrm{H}]^{+}[47]$. Therefore the origin for the observed

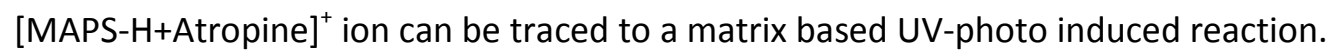

\section{Conclusion}

The present work has addressed a study on the adducts formed by various nucleophiles with a compound that has shown valuable properties as MALDI matrix. The performance of MAPS has indeed been related to its tendency to combine with the analyte. The focus has thus been on the charged adducts obtained by ESI of an acetonitrile solution, where MAPS is stable, in the presence of various additives. In some cases, a second component has been added to form a mixed solvent system (i.e. a mixture of acetonitrile with water or methanol). The combined evidence obtained by the CID behavior and IRMPD spectra speak in favor of covalently bound adducts whereby the incoming nucleophile $\left(\mathrm{MH}=\mathrm{H}_{2} \mathrm{O}, \mathrm{NH}_{3}, \mathrm{CH}_{3} \mathrm{OH}\right.$, and so on) has dismantled the maleic anhydride functionality yielding a free carboxylic group $(-\mathrm{C}(=\mathrm{O}) \mathrm{OH})$ together with a $-\mathrm{C}(=\mathrm{O}) \mathrm{OM}$ unit. In this kind of reactivity the protonated site, whereby the additional proton is shared between the two dimethylamino groups in 1 and 8 positions of the naphthalene frame, merely acts as charged label. The IRMPD spectra reported for the $\mathrm{H}_{2} \mathrm{O}$ and $\mathrm{NH}_{3}$ adducts are characterized by a distinct absorption at 3563 and $3558 \mathrm{~cm}^{-1}$, respectively, wavenumbers that are close to the $\mathrm{OH}$ stretching frequency of $3583 \mathrm{~cm}^{-1}$ for free, gaseous acetic acid [48]. From a chemical point of view, the possibility to form a carboxylic group upon attack of the nucleophile on the maleicanhydrido functional group appears to be a requisite in order to observe an addition product. Thus, only those molecules possessing a mobile proton on the nucleophilic site $(\mathrm{MH})$ succeed in forming an adduct with protonated MAPS where the 
maleicanhydrido functionality is converted into carboxylic group and $-\mathrm{C}(=\mathrm{O}) \mathrm{OM}$ unit. This feature explains the reactivity observed with ammonia and a secondary amine such as piperidine while 4-methylimidazole and pyridine appear unreactive. Amino acids may react as well by the $\beta$-amino group. The observed reactivity pattern may be peculiar of the dipolar aprotic solvent used in the ESI sampling of adduct ions. It is conceivable that in more complex systems the interaction of MAPS with selected analytes may be subtly further modulated.

This chemical characterization obtained by ESI-MS and IRMPD spectroscopy has been applied in the ontissue detection and mapping of atropine, a molecule having a mobile proton in the chemical structure, directly on the Atropa belladonna berry by MALDI-MSI. The results have verified an on-tissue covalent adduct formation with MAPS and consequently a derivatization-based approach for detection and localization of secondary metabolites such as atropine. It is thus shown a valid chemical approach to allow the on-tissue detection of small metabolites without any interference due to exclusively matrix ions.

The specific ability of MAPS to chemically react with analytes needs to be properly handled in MALDI-MSI applications. It is in fact highly promising in a perspective to discriminate among similar molecules (e. g. isomers) possessing different functional groups and in enhancing the display of specific classes of compounds, so to develop a strategy aiding in the interpretation of complex tissue samples. At the same time it may require a knowledgeable examination of the analytes of interest, particularly with regard to their acid/base and nucleophilic properties or the presence of mobile protons, to become an increasingly powerful tool.

In conclusion the determination of chemical and structural properties of gaseous ions by ESI-MS and IRMPD spectroscopy is a valid and promising contribution for the understanding of new analyte-matrix reactivity useful in the interpretation and design of MALDI-MSI procedures.

Acknowledgements The authors acknowledge funding for this study provided by Università di Roma "La Sapienza", by the Graduate Cluster Industrial Biotechnology (CLIB2021) and by the European Community's Horizon 2020 Programme (INFRAIA-02-2017, under Grant Agreement No. 731077).

\section{Compliance with ethical standards}

Conflict of interest The authors declare that they have no conflict of interest.

\section{References}

1. Fack F, Tardito S, Hochart G, Oudin A, Zheng L, Fritah S, Golebiewska A, Nazarov P V, Bernard A, Hau A, Keunen O, Leenders W, Lund-Johansen M, Stauber J, Gottlieb E, Bjerkvig R, Niclou SP. Altered metabolic landscape in IDH-mutant gliomas affects phospholipid, energy, and oxidative stress pathways. EMBO Mol Med. 2017;9:1681-1695.

2. Dekker TJA, Jones EA, Corver WE, van Zeijl RJM, Deelder AM, Tollenaar RAEM, Mesker WE, Morreau $\mathrm{H}, \mathrm{McDonnell}$ LA. Towards imaging metabolic pathways in tissues. Anal Bioanal Chem. 2015;407:2167-2176.

3. Trim PJ, Snel MF. Small molecule MALDI MS imaging: Current technologies and future challenges. Methods. 2016;104:127-141.

4. Karas M, Krüger R. Ion formation in MALDI: The cluster ionization mechanism. Chem Rev. 2003;103:427-439.

5. Knochenmuss R. Ion formation mechanisms in UV-MALDI. Analyst. 2006;131:966-986. 
6. Baker TC, Han J, Borchers $\mathrm{CH}$. Recent advancements in matrix-assisted laser desorption/ionization mass spectrometry imaging. Curr Opin Biotechnol. 2017;43:62-69.

7. Calvano CD, Monopoli A, Cataldi TRI, Palmisano F. Maldi matrices for low molecular weight compounds: an endeless story? Anal Bioanal Chem. 2018;410:4015-4038.

8. Shroff $R$, Svatoš A. Proton sponge: A novel and versatile MALDI matrix for the analysis of metabolites using mass spectrometry. Anal Chem. 2009;81:7954-7959.

9. Thomas A, Charbonneau JL, Fournaise E, Chaurand P. Sublimation of new matrix candidates for high spatial resolution imaging mass spectrometry of lipids: Enhanced information in both positive and negative polarities after 1,5-diaminonapthalene deposition. Anal Chem. 2012;84:2048-2054.

10. Swor CD, Zakharov LN, Tyler DR. A colorimetric proton sponge. J Org Chem. 2010;75:6977-6979.

11. Ozeryanskii V a., Pozharskii AF. Simple and hydrolytically stable proton sponge based organic cation displaying hydrogen bonding and a number of related phenomena. Tetrahedron. 2013;69:21072112.

12. Giampà M, Lissel MB, Patschkowski T, Fuchser J, Hans VH, Gembruch O, Bednarz H, Niehaus K. Maleic anhydride proton sponge as a novel MALDI matrix for the visualization of small molecules (<250: M / z) in brain tumors by routine MALDI ToF imaging mass spectrometry. Chem Commun. 2016;52:9801-9804.

13. Shroff R, Rulisek L, Doubsky J, Svatos A. Acid-base-driven matrix-assisted mass spectrometry for targeted metabolomics. Proc Natl Acad Sci. 2009;106:10092-10096.

14. Napagoda M, Rulíšek L, Jančařík A, Klívar J, Šámal M, Stará IG, Starý I, Šolínová V, Kašička V, Svatoš A. Azahelicene superbases as MAILD matrices for acidic analytes. ChemPlusChem. 2013;78:937-942.

15. Marshall AG, Hendrickson CL, Jackson GS. Fourier transform ion cyclotron resonance mass spectrometry: A primer. Mass Spectrom Rev. 1998;17:1-35.

16. Oomens J, Sartakov BG, Meijer G, von Helden G. Gas-phase infrared multiple photon dissociation spectroscopy of mass-selected molecular ions. Int J Mass Spectrom. 2006;254:1-19.

17. Polfer NC. Infrared multiple photon dissociation spectroscopy of trapped ions. Chem Soc Rev. 2011;40:2211-2221

18. Roithová J. Characterization of reaction intermediates by ion spectroscopy. Chem Soc Rev. 2012;41:547-559

19. Fridgen TD. Infrared consequence spectroscopy of gaseous protonated and metal ion cationized complexes. Mass Spectrom Rev. 2009;28:586-607.

20. Eyler JR. Infrared multiple photon dissociation spectroscopy of ions in Penning traps. Mass Spectrom Rev 2009;28:448-467.

21. MacAleese L, Maître P. Infrared spectroscopy of organometallic ions in the gas phase: From model to real world complexes. Mass Spectrom Rev. 2007;26:583-605.

22. Sinha RK, Maître P, Piccirillo S, Chiavarino B, Crestoni ME, Fornarini S. Cysteine radical cation: A distonic structure probed by gas phase IR spectroscopy. Phys Chem Chem Phys. 2010;12:9794-9800.

23. Filippi A, Fraschetti C, Piccirillo S, Rondino F, Botta B, D'Acquarica I, Calcaterra A, Speranza M. Chirality effects on the IRMPD spectra of basket resorcinarene/nucleoside complexes. Chem Eur J. 2012;18:8320-8328.

24. Prell JS, O'Brien JT, Williams ER. IRPD spectroscopy and ensemble measurements: Effects of different data acquisition and analysis methods. J Am Soc Mass Spectrom. 2010;21:800-809. 
25. Frisch MJ, Trucks GW, Schlegel HB, Scuseria GE, Robb MA, Cheeseman JR, Scalmani G, Barone V, Mennucci B, Petersson GA, Nakatsuji H, Caricato M, Li X, Hratchian HP, Izmaylov AF, Bloino J, Zheng G, Sonnenberg JL, Hada M, Ehara M, Toyota K, Fukuda R, Hasegawa J, Ishida M, Nakajima T, Honda Y, Kitao O, Nakai H, Vreven T, Montgomery Jr. JA, Peralta JE, Ogliaro F, Bearpark M, Heyd JJ, Brothers E, Kudin KN, Staroverov VN, Kobayashi R, Normand J, Raghavachari K, Rendell A, Burant JC, Iyengar SS, Tomasi J, Cossi M, Rega N, Millam JM, Klene M, Knox JE, Cross JB, Bakken V, Adamo C, Jaramillo J, Gomperts R, Stratmann RE, Yazyev O, Austin AJ, Cammi R, Pomelli C, Ochterski JW, Martin RL, Morokuma K, Zakrzewski VG, Voth GA, Salvador P, Dannenberg JJ, Dapprich S, Daniels AD, Farkas Ö, Foresman JB, Ortiz J V, Cioslowski J, Fox DJ (2009) Gaussian 09, Revision D.01. Gaussian Inc Wallingford CT. doi: 10.1159/000348293

26. Lee C, Yang W, Parr RG. Development of the Colle-Salvetti correlation-energy formula into a functional of the electron density. Phys Rev B. 1988;37:785-789.

27. Becke AD. Density-functional thermochemistry. III. The role of exact exchange. J Chem Phys. 1993;98:5648-5652.

28. Chiavarino B, Crestoni ME, Fornarini S, Scuderi D, Salpin JY. Interaction of cisplatin with 5'-dgmp: A combined irmpd and theoretical study. Inorg Chem. 2015;54:3513-3522.

29. Corinti D, Coletti C, Re N, Piccirillo S, Giampà M, Crestoni ME, Fornarini S. Hydrolysis of cis- and transplatin: structure and reactivity of the aqua complexes in a solvent free environment. RSC Adv. 2017;7:15877-15884.

30. Lias SG, Bartmess JE, Liebman JF, Holmes JL, Levin RD. (2016) Ion Energetics Data in NIST Chemistry WebBook, NIST Standard Reference Database Number 69, Eds. PJ Linstrom and WG Mallard, National Institute of Standards and Technology, Gaithersburg MD, 20899.

31. Turecek F, Moss CL, Pikalov I, Pepin R, Gulyuz K, Polfer NC, Bush MF, Brown J, Williams J, Richardson K. Gas-phase structures of phosphopeptide ions: A difficult case. Int J Mass Spectrom. 2013;354:249-256.

32. Wang D, Gulyuz K, Stedwell CN, Yu L, Polfer NC. Effect of phenol and acidic side chains on the protonation sites of b2ions confirmed by IRMPD spectroscopy. Int J Mass Spectrom. 2012;330:144151.

33. Yacovitch TI, Heine N, Brieger C, Wende T, Hock C, Neumark DM, Asmis KR. Vibrational spectroscopy of bisulfate/sulfuric acid/water clusters: Structure, stability, and infrared multiple-photon dissociation intensities. J Phys Chem A. 2013;117:7081-7090.

34. Chiavarino B, Crestoni ME, Schütz M, Bouchet A, Piccirillo S, Steinmetz V, Dopfer O, Fornarini S. Cation-pi interactions in protonated phenylalkylamines. J Phys Chem A. 2014;118:7130-7138.

35. Corinti D, Coletti C, Re N, Chiavarino B, Crestoni ME, Fornarini S. Cisplatin binding to biological ligands revealed at the encounter complex level by IR action spectroscopy. Chem Eur J. 2016;22:3794-3803.

36. Corinti D, De Petris A, Coletti C, Re N, Chiavarino B, Crestoni ME, Fornarini S. Cisplatin primary complex with I-histidine target revealed by IR multiple photon dissociation (IRMPD) spectroscopy. ChemPhysChem. 2017;18:318-325.

37. Zehnacker A. Chirality effects in gas-phase spectroscopy and photophysics of molecular and ionic complexes: Contribution of low and room temperature studies. Int Rev Phys Chem. 2014;33:151207.

38. Voronina L, Rizzo TR. Spectroscopic studies of kinetically trapped conformations in the gas phase: the case of triply protonated bradykinin. Phys Chem Chem Phys. 2015;17:25828-25836. 
39. Scott Hopkins W, Marta RA, Steinmetz V, McMahon TB. Mode-specific fragmentation of amino acidcontaining clusters. Phys Chem Chem Phys. 2015;17:28548-28555.

40. Graham Cooks R, Patrick JS, Kotiaho T, McLuckey SA. Thermochemical determinations by the kinetic method. Mass Spectrom Rev. 1994;13:287-339.

41. McLuckey SA, Cameron D, Cooks RG. Proton Affinities from Dissociations of Proton-Bound Dimers. J Am Chem Soc. 1981;103:1313-1317.

42. Kohnen KL, Sezgin S, Spiteller M, Hagels H, Kayser O. Localization and Organization of Scopolamine Biosynthesis in Duboisia myoporoides R. Br. Plant Cell Physiol. 2018;59:107-118.

43. Dong Y, Li B, Malitsky S, Rogachev I, Aharoni A, Kaftan F, Svatoš A, Franceschi P. Sample Preparation for Mass Spectrometry Imaging of Plant Tissues: A Review. Front Plant Sci. 2016;7:60.

44. Ashtiania F, Sefidkonb F. Tropane alkaloids of Atropa belladonna L. and Atropa acuminata Royle ex Miers plants. J Med Plants Res. 2011;29:6515-6522.

45. Robinson KN, Steven RT, Bunch J. Matrix optical absorption in UV-MALDI MS. J Am Soc Mass Spectrom 2018;29:501-511.

46. Ehring $\mathrm{H}$, Karas $\mathrm{M}$, Hillenkamp $\mathrm{F}$. Role of photoionization and photochemistry in ionization processes of organic molecules and relevance for matrix-assisted laser desorption lonization mass spectrometry. Org Mass Spectrom. 1992;27:472-480.

47. Calvano CD, Monopoli A, Ditaranto N, Palmisano F. 1,8-Bis(dimethylamino)naphthalene/9aminoacridine: A new binary matrix for lipid fingerprinting of intact bacteria by matrix assisted laser desorption ionization mass spectrometry. Anal Chim Acta. 2013;798:56-63.

48. Shimanouchi T. Tables of Molecular Vibrational Frequencies. Consolidate Volume I. National Bureau of Standards; 1972. 